\begin{tabular}{|c|c|c|}
\hline $\begin{array}{l}\text { PKS } \\
\text { PUBLIC } \\
\text { KNOWLEDGE } \\
\text { NOWLDG }\end{array}$ & $\begin{array}{c}\text { REVISTA DE GEOGRAFIA } \\
\text { (RECIFE) } \\
\text { http://www.revista.uffe.br/revistageografia }\end{array}$ & $\begin{array}{l}\text { OJS } \\
\text { OPEN } \\
\text { JPUNANAL } \\
\text { SYSTESS }\end{array}$ \\
\hline
\end{tabular}

\title{
TENDÊNCIAS PLUVIAIS E ANÁLISE DA MÉDIA MÓVEL PARA SÃO BENTO DO UNA-PE, BRASIL
}

\author{
Raimundo Mainar de Medeiros ${ }^{1}$, Romildo Morant de Holanda ${ }^{2}$, Vicente de Paulo Silva ${ }^{3}$, \\ Cristiano José da Silva ${ }^{4}$
}

${ }^{1}$ Pós-Doc.,Dr.,Universidade Federal Rural de Pernambuco, UFRPE, PE, Brazil e-mail: mainarmedeiros@gmail.com

${ }^{2}$ Prof. Dr. Universidade Federal Rural de Pernambuco, UFRPE, PE, Brazil, e-mail: romildomorant@gmail.com

${ }^{3}$ Prof. Dr. Universidade Federal Rural de Pernambuco, UFRPE, PE, Brazil, e-mail:vicenteufrpe@yahoo.com.br

${ }^{4}$ Mestrando da Universidade Federal Rural de Pernambuco, UFRPE, PE, Brazil, e-mail:crisjs45@yahoo.com.br

Artigo recebido em 23/06/2017e aceito em 15/01/2018

\begin{abstract}
RESUMO
Estudar as variabilidades pluviais no município de São Bento do Una torna-se ressaltante na medida em que se observa o município como importante centro aviário, que vem passando por necessidades hídricas. Objetiva-se analisar as distribuições das precipitações pluviais durante o período de 1920 a 2016, examinar os possíveis comportamento da tendência linear e a variabilidade do coeficiente de regressão, levando em consideração a avaliação mensal e visando identificar os meses com maiores e menores pluviosidade assim com sua variação temporal. O estudo pode ser utilizado como ferramenta para planejamentos e ações que visem forma de gerenciar os recursos hídricos utilizando sistemas de captação, armazenamento e evitando a problemática da escassez de água. Há a necessidade de políticas e planos de captação e aproveitamento das águas das chuvas, além do uso eficiente dos demais recursos naturais da região, para que o desenvolvimento socioeconômico não seja limitado pela disponibilidade hídrica. Permanece a necessidade de estudos mais aprofundados sobre a distribuição pluviométrica da região Nordeste do Brasil e em especial na área em estudo, visando à identificação de padrões de chuvas, medidas preventivas contra as secas e armazenamento de água para sobrevivência humana e animal. Palavras-chaves: deficiência e excedente hídrico; armazenamento água; planejamento hídrico.
\end{abstract}

\section{PLURAL TRENDS AND ANALYSIS OF THE MOBILE AVERAGE FOR SÃO BENTO DO UNA-PE, BRAZIL}

\begin{abstract}
SUMMARY
Studying the rainfall variability in the municipality of São Bento do Una becomes salient in that the municipality is observed as an important aviary center, which has been passing through water needs. The objective of this study was to analyze the distributions of rainfall during the period 1920 to 2016, to examine the possible behavior of the linear trend and the variability of the regression coefficient, taking into account the monthly evaluation and to identify the months with higher and lower rainfall, its temporal variation. The study can be used as a tool for planning and actions aimed at managing water resources using capture, storage and avoiding the problems of water scarcity. There is a need for policies and plans for capturing and utilizing rainwater, in addition to the efficient use of other natural resources in the region, so that socioeconomic development is not limited by water availability. There is a need for more in-depth studies on the rainfall distribution of the Northeast region of Brazil and especially in the study area, aiming at the identification of rainfall patterns, preventive measures against droughts and water storage for human and animal survival.
\end{abstract}

Keywords: water deficit and surplus; water storage; water planning. 


\section{INTRODUÇÃO}

Waylen et al. (2014) definiram clima como algo que é esperado, enquanto o tempo é algo observado num dado instante ou período de tempo de curta duração. Para a climatologia, este mesmo conceito serve para descrever a possibilidade de eventos extremos, período ou intervalo de retorno, que é o intervalo de tempo médio esperado entre eventos de maior ou menor magnitude.

O monitoramento pluvial é preocupação global e, por isso, políticas de previsão dos totais de chuva vêm sendo adotadas em todo o mundo visando o armazenamento e represamento de água das chuvas. Nesse sentido, diversos mecanismos de alerta quanto à escassez ou excesso dos recursos hídricos tornam-se cada vez mais comuns especialmente para o setor avícola e agropecuário. De acordo com Sun et al. (2014) que acreditam nas evidências entre a distribuição das variáveis meteorológicas e os modos de variabilidade climática em diferentes regiões do globo terrestre.

Em conformidade com os autores Amanajás et al. (2012) e Moura (2014) a produtividade agropecuária está associada à variabilidade espaço-temporal da precipitação, verificaram que estas variações se constituem como fatores responsáveis pela alternância das produções anuais, contribuindo significativamente nas perdas e ganhos da produção. A irregularidade no quantitativo e distribuição espacial da chuva é fatores limitantes para o desenvolvimento da produção agrícola na Amazônia.

A variabilidade da precipitação é atributo climático importante. As informações dessas características podem nortear decisões com vistas à mitigação de danos decorrentes da irregularidade das chuvas. Os fatores provocadores e/ou inibidores de chuvas quando da atuação de seus períodos podem provocar excesso ou seca de acordo com Medeiros (2016).

Segundo Pereira (2014), verificou que na região do semiárido nordestino, quando analisado alguns núcleos com tendência atuais, observou que nos estados de Pernambuco, Paraíba, Ceará e Bahia, obtiveram tendência negativa, onde a precipitação variou de 1 a 5 $\mathrm{mm} / \mathrm{ano}$.

Tem-se por objetivo analisar as distribuições das precipitações pluviais durante o período de 1920 a 2016, examinar os possíveis comportamento da tendência linear (crescente ou decrescente), e a variabilidade do coeficiente de regressão, levando em consideração a avaliação mensal dos anos, com o intuito de identificar os meses com maiores e menores pluviosidade, visando informações com relação à variação espacial e temporal pluvial em São Bento do Una. 


\section{MATERIAL E MÉTODO}

São Bento do Una localiza-se na mesorregião Agreste e na Microrregião do Vale do Ipojuca do Estado de Pernambuco, limitando-se a norte com Belo Jardim, a sul com Jucati, Jupi e Lajedo, a leste com Cachoeirinha, e a oeste com Capoeiras, Sanharó e Pesqueira. (Figura 1).

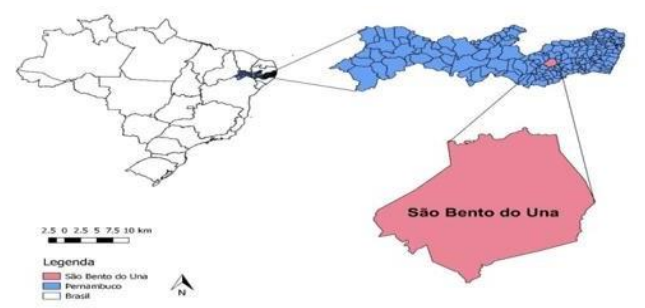

Figura 1. Localização do município de São Bento do Una no estado do Pernambuco.

A área municipal ocupa $719,15 \mathrm{~km}^{2}$ e representa $0.72 \%$ do Estado de Pernambuco. A sede do município tem altitude de 614 metros e coordenadas geográficas de $08^{\circ} 31^{\prime} 22^{\prime}$ ' de latitude sul e $36^{\circ} 06^{\prime} 40^{\prime \prime}$ de longitude oeste. Com população estimada de 58.251 habitantes com densidade demográfica de 74,03 hab $/ \mathrm{km}^{2}$.

São Bento do Una encontra-se inserido, geologicamente, na Província Borborema, sendo constituído pelos litotipos da Suíte Serra de Taquaritinga dos complexos Cabrobó e Belém do São Francisco e da Suíte Intrusiva Leucocrática Peraluminosa como pode ser observado na figura 2.

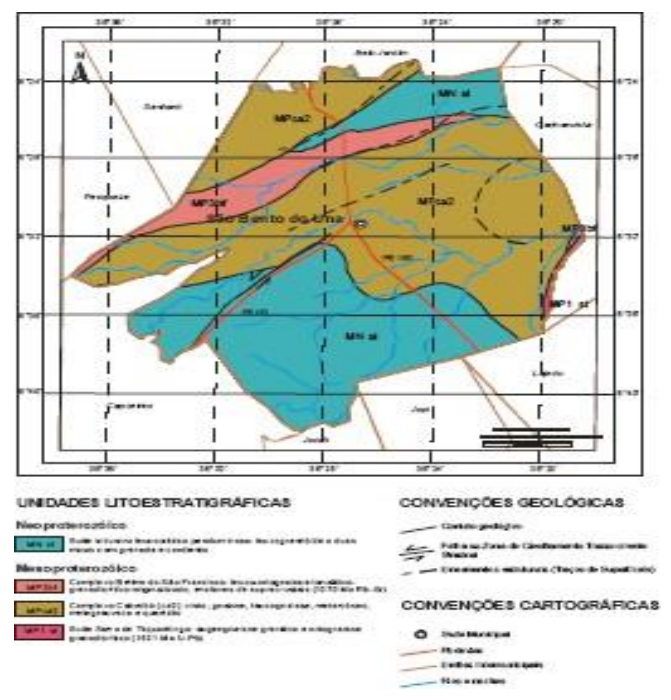

Figura 2. Mapa Geológico municipal. Fonte: CPRM (2005).

São Bento do Una está inserido na unidade geoambiental do Planalto da Borborema, formada por maciços e outeiros altos, com altitude variando entre 650 a 1.000 metros.

Ocupa uma área de arco que se estende do sul de Alagoas até o Rio Grande do Norte. 
O relevo é geralmente movimentado, com vales profundos e estreitos dissecados. Com respeito à fertilidade dos solos é bastante variada, com certa predominância de média para alta.

Nas Superfícies suaves onduladas a onduladas, ocorrem os Planossolos, medianamente profundos, fortemente drenados, ácidos a moderadamente ácidos e fertilidade natural média e ainda os Podzólicos, que são profundos, textura argilosa, e fertilidade natural média a alta. Nas elevações ocorrem os solos Litólicos, rasos, textura argilosa e fertilidade natural média. Nos Vales dos rios e riachos, ocorrem os Planossolos, medianamente profundos, imperfeitamente drenados, textura média/argilosa, moderadamente ácidos, fertilidade natural alta e problemas de sais. Ocorrem ainda afloramentos de rochas.

A área da unidade é recortada por rios perenes, porém de pequena vazão e o potencial de água subterrânea é baixo.

A vegetação desta unidade é formada por Florestas Subcaducifólica e Caducifólica, próprias das áreas agrestes.

Segundo o modelo de classificação climática de Köppen (1928) São Bento do Una tem o clima do tipo As Tropical Chuvoso, com verão seco, esta classificação esta de acordo com Alvares et al. (2014) e com Medeiros (2018).

A quadra chuvosa se inicia em fevereiro com chuvas de pré-estação (chuvas que antecedem o período da quadra chuvosa) com seu término ocorrendo no final do mês de agosto e podendo se prolongar até a primeira quinzena de setembro. O trimestre chuvoso centra-se nos meses de maio, junho e julho, o trimestre seco ocorrem entre outubro, novembro e dezembro, a precipitação anual é de $606 \mathrm{~mm}$, as variações pluviais mensais oscilam entre 19,6 mm no mês de outubro a 92,3 mm no mês de março. Os fatores provocadores de chuvas no município são a contribuição da Zona de Convergência Intertropical (ZCIT), formação dos vórtices ciclônicos de altos níveis (VCAS), contribuição dos ventos alísios de nordeste no transporte de vapor e umidade os quais condensam e forma nuvens provocando chuvas de moderadas a fortes, formações das linhas de instabilidades, orografia e suas contribuições local e regional segundo Medeiros (2016).

Os dados pluviométricos foram adquiridos da Superintendência do Desenvolvimento do Nordeste (SUDENE, 1990), Agencia Pernambucana de Água e Clima (APAC, 2017) compreendido entre os anos de 1920 a 2016. Utilizou-se de cálculos simplificados estatisticamente para definir, média, desvio padrão, coeficiente de variância, máximos e mínimos valores absolutos ocorridos. 
A limitação dos recursos hídricos na atualidade é importante condicionante ao desenvolvimento econômico e social, acarretando inúmeros desafios ao planejamento e gerenciamento deste recurso em conformidade com Sousa et al. (2015). As falhas de dados ocorridas entre a década de 90 pode ser explicada pela troca de responsabilidade na coleta dos registros pluviométricos da antiga SUDENE para o LAMEPE, neste período de transição as estações passaram por manutenção e outras foram implantadas em algumas cidades dentre 1989 e 1992. Para tanto foram realizados preenchimentos de falhas pelo método da média aritmética dos postos vizinhos, homogeneização e consistência nos referidos dados para podese trabalhar e fornecer informações confiáveis.

Os dados de precipitação climatológica média mensal foram agrupados em 96 anos, caracterizando um período de normal climatológica, totais anuais de precipitação do período de 1920 a 2016, plotando os seus respectivos gráficos e tendências. Os referidos dados foram fornecidos pela Agencia de água e clima do Estado de Pernambuco (APAC, 2017).

Utilizou-se do cálculo da estatística básica para a realização da média, desvio padrão, mediana, coeficiente variância e dos valores máximos e mínimos absolutos, utilizou-se da equação linear para definir a equação da reta, $\mathrm{R}^{2}$,

\section{RESULTADOS E DISCUSSÃO}

Nas figuras de 3 a 16 realizaram-se as analises mensais e suas tendências lineares seguidamente do nível de significância $\left(\mathrm{R}^{2}\right)$ na área estudada, com o intuito de verificação de registro de acréscimo e/ou decréscimo pluviais futuramente.

A figura 3 destaca-se os anos de 1925, 1940, 1944, 1955, 1966, 1981, 1987, 2002 a 2004 e 2010 com ocorrências de precipitações acima da média. Visualiza-se a tendência da reta com coeficiente angular positivo e $\mathrm{R}^{2}$ sem significância implicando que a possibilidade de aumento nos índices pluviais e praticamente inexistente de ocorrência.

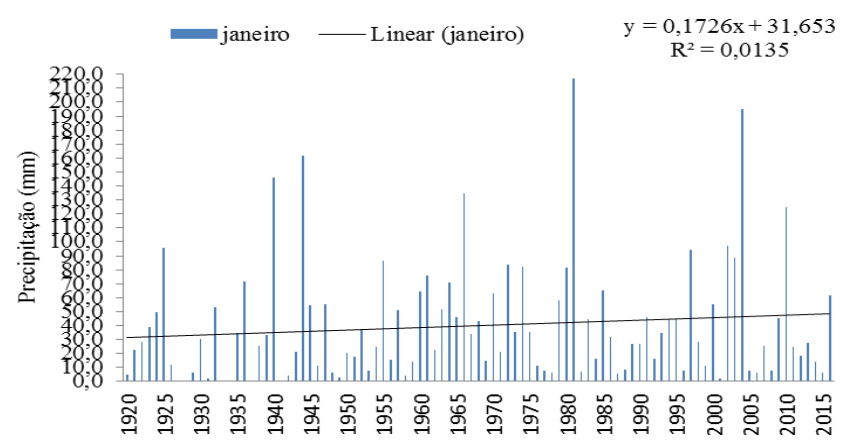

Figura 3. Distribuição temporal da precipitação do mês de janeiro compreendido entre o período de 1920 a 2016 e sua tendência de regressão linear para o município de São Bento do Una. 
$\mathrm{Na}$ figura 4 tem-se a distribuição temporal da precipitação do mês de fevereiro compreendido entre o período de 1920 a 2016 e sua tendência de regressão linear para o a área estudada. Com coeficiente angular negativo e $\mathrm{R}^{2}$ insignificante o qual se espera que armazenamento e represamento de água sejam insuficientes ao abastecimento.

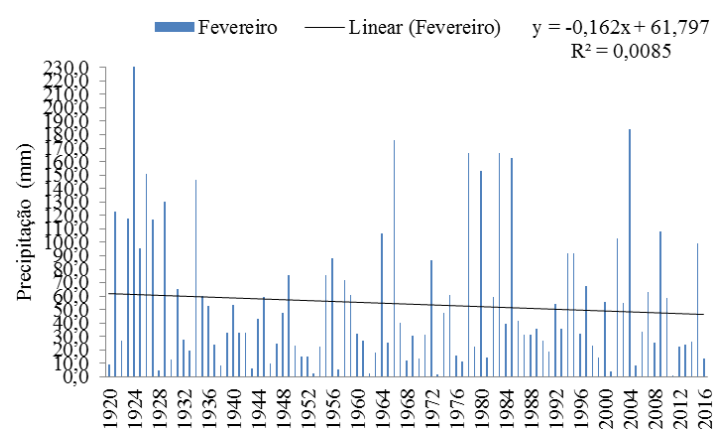

Figura 4. Distribuição temporal da precipitação do mês de fevereiro compreendido entre o período de 1920 a 2016 e sua tendência de regressão linear para o município de São Bento do Una.

Com nível de significância baixo e de coeficiente angular positivo a tendência da reta não tem variabilidade, significando que os atuais índices pluviais podem ocorrer, com oscilações entre $0,5 \mathrm{~mm}$ a $300 \mathrm{~mm}$. Nesta ocorrência não é descartado eventos extremos de alta magnitude e em curto intervalo de tempo, não sendo eventos benéficos à agropecuária local conforme figura 5.

Estudo similares foram realizado por Medeiros et al. (2015) para o município de Cabaceiras - PB, demostraram que $\mathrm{R}^{2}$ apresentaram baixas significâncias.

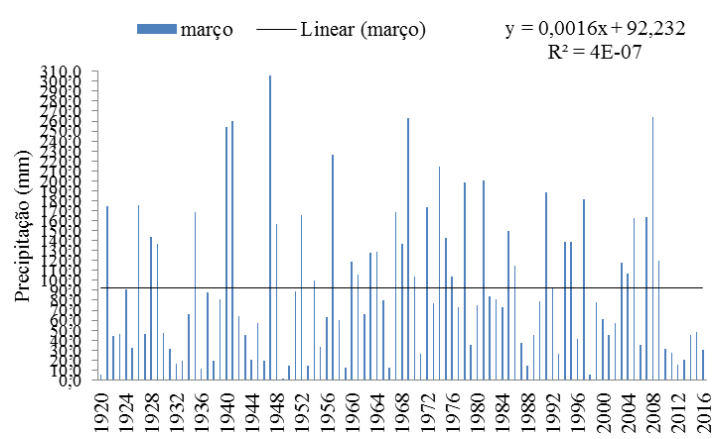

Figura 5. Distribuição temporal da precipitação do mês de março compreendido entre o período de 1920 a 2016 e sua tendência de regressão linear para o município de São Bento do Una.

Abril considerado como mês chuvoso apresenta-se com irregularidades pluviais Inter anual (figura 6) mostrando flutuações de $10 \mathrm{~mm}$ a $330 \mathrm{~mm}$. A reta de tendência com coeficiente angular positivo $\mathrm{R}^{2}$ de baixa significância apresenta-se como neutra demonstrando possível continuidade das flutuações irregulares. 


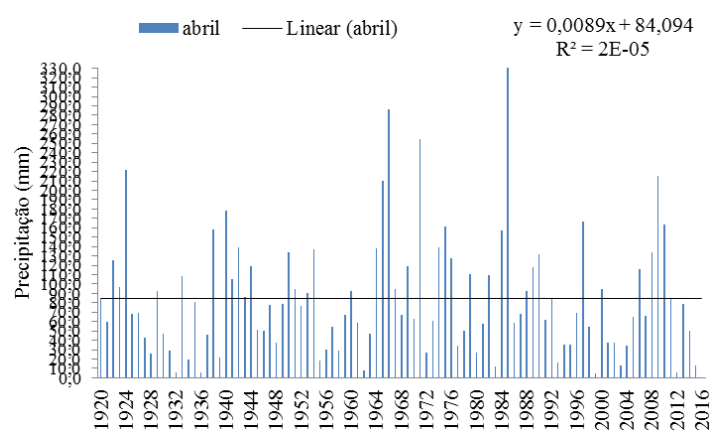

Figura 6. Distribuição temporal da precipitação do mês de abril compreendido entre o período de 1920 a 2016 e sua tendência de regressão linear para o município de São Bento do Una.

Em pleno período chuvoso (maio) as contribuições pluviais não são regulares e suas flutuações oscilam entre $5 \mathrm{~mm}$ a $270 \mathrm{~mm}$ de acordo com a figura 7, destaca-se a tendência da reta com coeficiente angular positivo e $\mathrm{R}^{2}$ de baixa significância demonstrando que estes eventos irregulares poderão serem repetidos prejudicando ainda mais os setores da agropecuária, avícola e armazenamento de água.

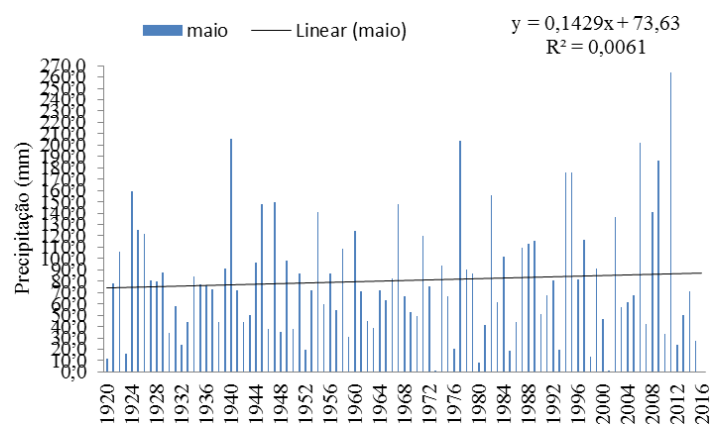

Figura 7. Distribuição temporal da precipitação do mês de maio compreendido entre o período de 1920 a 2016 e sua tendência de regressão linear para o município de São Bento do Una.

A tendência de regressão linear do mês de junho entre o período de 1920 a 2016 apresentou coeficiente angular positivo e $\mathrm{R}^{2}$ sem significância, à distribuição temporal da pluviometria oscilou entre $10 \mathrm{~mm}$ no mês de junho de 1960 a $310 \mathrm{~mm}$ no ano 2010 (figura 8).

Estudo do mesmo gênero foi realizado por Medeiros et al. (2016) para a área da bacia hidrográfica do Rio Uruçuí, demonstrando que $\mathrm{R}^{2}$ apresentaram correlações entre 0,48 a 0,93 . 


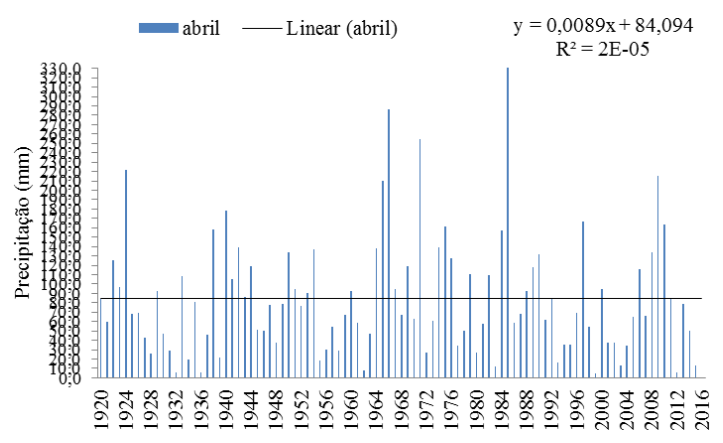

Figura 8. Distribuição temporal da precipitação do mês de junho compreendido entre o período de 1920 a 2016 e sua tendência de regressão linear para o município de São Bento do Una.

Com tendência de regressão linear positiva e $\mathrm{R}^{2}$ com baixa significância o mês de julho (figura 9) apresenta-se com altas variabilidades pluviais fluindo entre $11 \mathrm{~mm}$ no ano de 1930 a 195,5 mm no ano de 1987. Estas variabilidades estão relacionadas às flutuações locais e regionais interligados aos fatores inibidores e/ou provocadores de chuvas da área estudada.

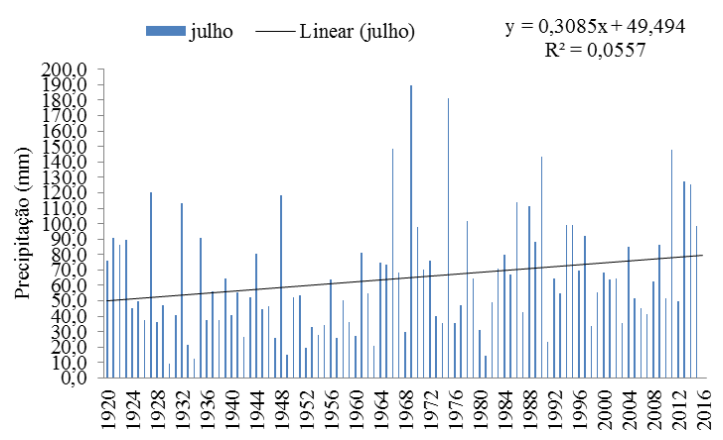

Figura 9. Distribuição temporal da precipitação do mês de julho compreendido entre o período de 1920 a 2016 e sua tendência de regressão linear para o município de São Bento do Una.

Segundo Marengo et al. (2011), a zona de convergência intertropical (ZCIT) é o importante sistema atmosférico causador de chuvas na região, que é representado pelo eixo do cavado equatorial e suas diferentes variações em posição e intensidade que estão correlacionadas às alterações nas posições e intensidades das altas subtropicais do Atlântico Norte e Sul.

Figura 10 tem-se $\mathrm{R}^{2}$ de baixa significância e com tendência de regressão linear positiva, as irregularidades ocorridas entre anos e característico da região, pois se localiza na região semiárida brasileira. As flutuações inter anuais fluem $2 \mathrm{~mm}$ em 1925 a 100,5 mm no ano 2009, espera-se a ocorrência de eventos extremos de alta magnitude e de curto intervalo de tempo conforme declaração de Marengo et al. (2015). 


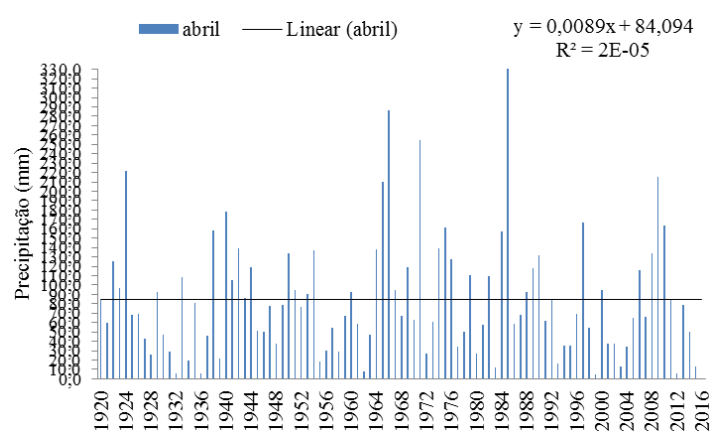

Figura 10. Distribuição temporal da precipitação do mês de agosto compreendido entre o período de 1920 a 2016 e sua tendência de regressão linear para o município de São Bento do Una.

Na Figura 11 tem-se a variabilidade temporal da precipitação do mês de setembro compreendido entre o período de 1920 a 2016 e sua tendência de regressão linear para o a área estudada. A tendência tem $\mathrm{R}^{2}$ inignificativo e seu coeficiente angular positivo. Destacamse as irregularidades ocorridas nos índices pluviais entre os anos de 1962 a 2006 com maior flutuabilidade isto, devido às condições locais auxiliados pelos sistemas de micro escala.

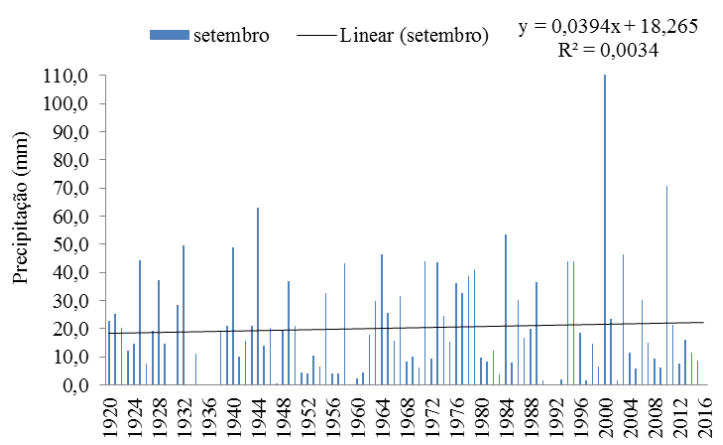

Figura 11. Distribuição temporal da precipitação do mês de setembro compreendido entre o período de 1920 a 2016 e sua tendência de regressão linear para o município de São Bento do Una.

O mês de outubro figura 12 compreendido ao período de 1920 a 2016 apresenta-se com coeficiente angular negativo e com nível de significância baixo, as flutuações pluviais fluem entre 0 mm no ano de 1955 a 150 mm em 1934, estas flutuações estão de acordo com Marengo et al. (2015). 


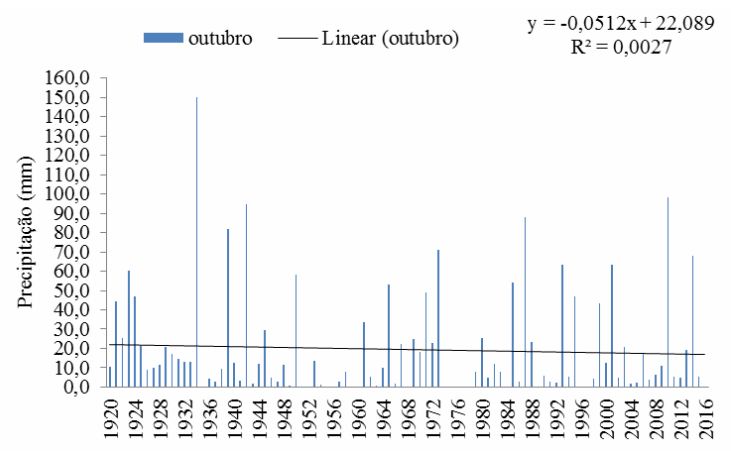

Figura 12. Distribuição temporal da precipitação do mês de outubro compreendido entre o período de 1920 a 2016 e sua tendência de regressão linear para o município de São Bento do Una.

Com coeficiente angular negativo e $\mathrm{R}^{2}$ de baixa significância conforme figura 13 . $\mathrm{O}$ mês de novembro é considerado seco devido às oscilações pluviais serem abaixo da climatologia exceto para mês anômalo como ocorrido nesta analise as quais se destacam os anos de 1921, 1949 e 2015 sendo considerado extremamente chuvoso.

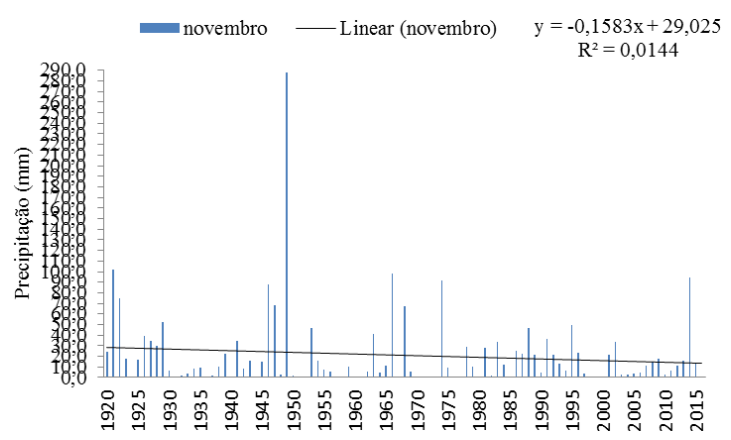

Figura 13. Distribuição temporal da precipitação do mês de novembro compreendido entre o período de 1920 a 2016 e sua tendência de regressão linear para o município de São Bento do Una.

A Figura 14 tem-se a variabilidade da distribuição temporal da precipitação do mês de dezembro compreendido entre o período de 1920 a 2016 e sua tendência de regressão linear para a área estudada.

O mês de dezembro caracterizado por tem baixos índices pluviométricos apresentou coeficiente angular negativo e $\mathrm{R}^{2}$ de baixa significância demonstrando que a possibilidade de eventos extremos é esperada.

Destacam-se os anos de 1925, 1963, 1969 e 1972 que se registraram chuvas anômalas e acima dos padrões normais e as irregularidades pluviais entre os anos de 1920 a 2016. Estas variabilidades estão correlacionadas com os fatores predominantes que atuaram na meso e micro escala e suas contribuições locais e regionais. 


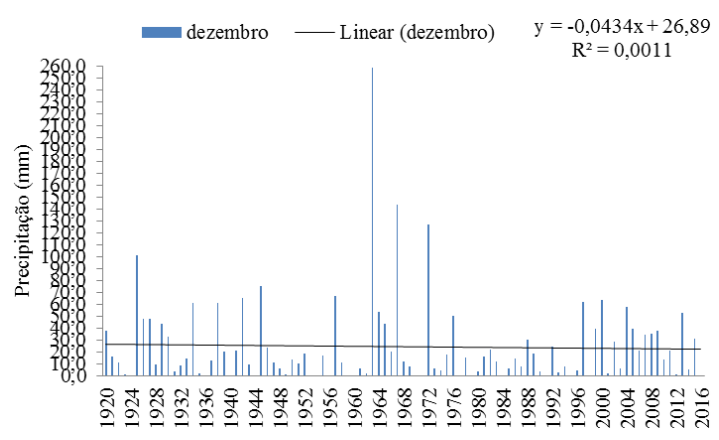

Figura 14. Distribuição temporal da precipitação do mês de dezembro compreendido entre o período de 1920 a 2016 e sua tendência de regressão linear para o município de São Bento do Una.

\section{TENDÊNCIA FUTURA MENSAL E ANUAL}

Na Tabela 1 verifica-se que os coeficientes de determinação da regressão não apresentaram significâncias para todos os meses, esta oscilação é decorrente do complexo diversificado da sazonalidade na área em estudo.

Os meses que tem coeficiente angular negativo são: fevereiro outubro, novembro e dezembro, nos demais meses estes coeficientes são positivos.

Tabela 1. Equação linear, coeficiente de determinação da regressão $\left(\mathrm{R}^{2}\right)$, média histórica mensal e total anual da precipitação pluvial da área estudada.

\begin{tabular}{llll}
\hline Meses & Equação linear & $\mathrm{R}^{2}$ & Média \\
\hline Janeiro & $\mathrm{Y}=0,1726 \mathrm{x}+31,653$ & 0,0135 & 40,1 \\
Fevereiro & $\mathrm{Y}=-0,162 \mathrm{x}+61,797$ & 0,0085 & 53,9 \\
Março & $\mathrm{Y}=0,0016 \mathrm{x}+92,232$ & $4 \times 10^{-7}$ & 92,3 \\
Abril & $\mathrm{Y}=0,0089 \mathrm{x}+84,094$ & $2 \times 10^{-5}$ & 84,5 \\
Maio & $\mathrm{Y}=0,1429 \mathrm{x}+73,630$ & 0,0061 & 80,6 \\
Junho & $\mathrm{Y}=0,211 \mathrm{x}+64,815$ & 0,0155 & 75,0 \\
Julho & $\mathrm{Y}=0,3085 \mathrm{x}+49,494$ & 0,0557 & 64,5 \\
Agosto & $\mathrm{Y}=0,1368 \mathrm{x}+27,493$ & 0,0309 & 33,6 \\
Setembro & $\mathrm{Y}=0,0394 \mathrm{x}+18,285$ & 0,0034 & 20,2 \\
Outubro & $\mathrm{Y}=-0,0512 \mathrm{x}+22,089$ & 0,0027 & 19,6 \\
Novembro & $\mathrm{Y}=-0,1583 \mathrm{x}+29,025$ & 0,0144 & 21,3 \\
Dezembro & $\underline{Y}=-0,0434 \mathrm{x}+26,890$ & $\underline{0,0011}$ & $\underline{24,8}$ \\
\cline { 1 - 2 } & & &
\end{tabular}

Observando-se a figura 15 nota-se que os meses de março, abril e maio concentramse os maiores índices mensais de precipitação, com valor médio do período de $606 \mathrm{~mm}$, correspondendo a $42 \%$ da precipitação anual. Os meses com os menores índices pluviométricos oscilam entre setembro, outubro e novembro que correspondem a $9 \%$ do total 
anual, mostrando-se ao longo do tempo, variabilidade temporal característico da região semiárida brasileira que demonstram a não possibilidade de acréscimo anual nos índices pluviométricos.

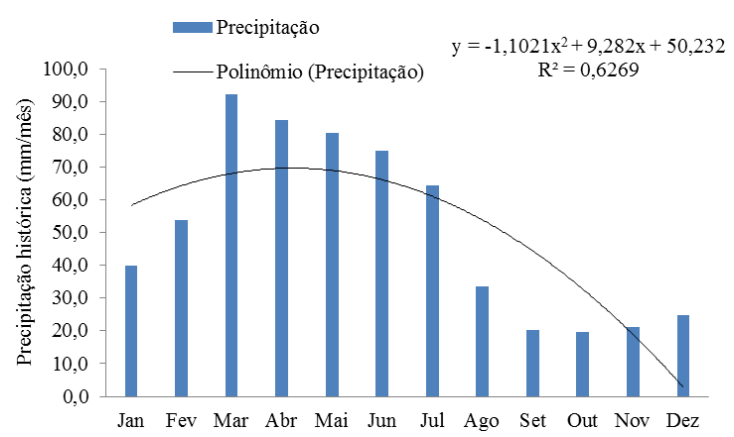

Figura 15. Histograma da média pluviométrica climatológica e tendência polinomial para o município de São Bento do Una.

Tendências negativas dos núcleos de precipitação, denotar o aumento nos tempos sem chuvas ao longo dos anos, tanto no período chuvoso quanto no período seco, os estudos posteriores não avaliaram se existe tendência crescente ou decrescente na acuidade da precipitação e no número de eventos extremos para a região semiárida do Nordeste do Brasil, com isso fica nítida a necessidade de se explorar maiores estudos, especialmente quando se trata de uma região semiárida como a nordestina, que convive com períodos prolongados de seca conforme afirmação de Costa et al. (2015).

\section{ANÁLISE ESTATÍSTICA}

Na Tabela 2 verifica-se que os valores da média e da mediana foram desconexos, mostrando que houve a presença de valores extremos discordantes na amostra. O mês de máximo índice pluviométrico é março com 92,3 mm, os menores índices ocorrem entre os meses de setembro e outubro com 20,2 e 19,6 mm respectivamente destaca-se que a mediana apresentaram valores inferiores a média para o referido período, ao passo que nos meses de menores precipitações a mediana foi nula e apresentou valor insignificante, mostrando a dispersão contundente dos dados. As variabilidades mensais na mediana indicam que esta medida de tendência central pode não ser o valor mais provável de ocorrer nesse tipo de distribuição. É notável ainda, que as médias mensais superam os valores medianos em alguns meses. Visto assim, os modelos de distribuição de chuvas mensais são assimétricos, com 
coeficiente de assimetria positivo. Portanto a mediana apresenta maior probabilidade de ocorrência que a média, de acordo com os resultados deparados por Almeida et al. (2007).

Segundo Galvani (2011) o desvio padrão é importante para terem-se informações do "grau de dispersão dos valores em relação ao valor médio". O coeficiente de variância que é utilizado para fazer comparações em termos relativos e expressa "a variabilidade de cada conjunto de dados normalizada em relação à média, em porcentagem.”

Tabela 2. Medidas de tendência central e de dispersão da área municipal de São Bento do Una.

\begin{tabular}{ccccccc}
\hline Meses & $\begin{array}{c}\text { Média } \\
(\mathrm{mm})\end{array}$ & $\begin{array}{c}\text { Desvio } \\
\text { Padrão }(\mathrm{mm})\end{array}$ & $\begin{array}{c}\text { Mediana } \\
(\mathrm{mm})\end{array}$ & $\begin{array}{c}\text { Coeficiente } \\
\text { Variância }(\%)\end{array}$ & $\begin{array}{c}\text { Precipitação } \\
\text { Máxima }(\mathrm{mm})\end{array}$ & $\begin{array}{c}\text { Precipitação } \\
\text { Mínima }(\mathrm{mm})\end{array}$ \\
\hline Janeiro & 40,1 & 41,7 & 43,5 & 1,04 & 217,2 & 0,0 \\
Fevereiro & 53,9 & 49,3 & 12,1 & 0,92 & 233,7 & 0,5 \\
Março & 92,3 & 70,5 & 137,1 & 0,76 & 305,9 & 0,1 \\
Abril & 84,5 & 62,4 & 67,2 & 0,74 & 332,5 & 4,6 \\
Maio & 80,6 & 51,1 & 66,9 & 0,63 & 263,6 & 0,8 \\
Junho & 75,0 & 47,3 & 50,9 & 0,63 & 292,8 & 8,2 \\
Julho & 64,5 & 36,4 & 29,8 & 0,56 & 189,8 & 9,4 \\
Agosto & 33,6 & 21,1 & 17,9 & 0,63 & 105,7 & 2,4 \\
Setembro & 20,2 & 18,7 & 8,4 & 0,93 & 112,6 & 0,0 \\
Outubro & 19,6 & 27,3 & 0,0 & 1,39 & 150,3 & 0,0 \\
Novembro & 21,3 & 36,7 & 67,0 & 1,72 & 287,5 & 0,0 \\
Dezembro & 24,8 & 36,4 & 11,9 & 1,47 & 259,2 & 0,0 \\
Anual & 606,0 & 196,0 & 512,7 & 0,32 & 1079,9 & 105,2 \\
\hline
\end{tabular}

\section{MÉDIA MÓVEL PARA 5 E 10 ANOS}

A figura 16 representa a precipitação observada e suas precipitações estimadas pelas médias móveis para 5 e 10 anos para a área em estudo.

O comportamento da precipitação observada segue as estimativas de vazões pela média móvel para 5 e 10 anos, o ritmo das precipitação observadas com redução de amplitude e achatamento entre anos. As estimativas das medias-móveis de 10 anos apresentam valores de maiores significâncias do que para os 5 anos.

Estudos semelhantes foram realizados por Galvíncio (2000) na precipitação do Rio São Francisco para (algum setor alto e médio do curso do rio). 


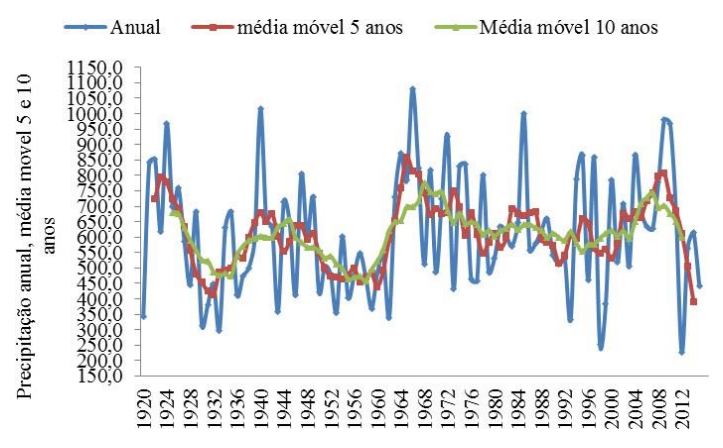

Figura 16. Precipitações: observadas, médias móveis para 5 e 10 anos para o município de São Bento do Una.

\section{CONCLUSÃO}

Este estudo pode ser ferramenta para planejamentos e ações que visem a melhor forma de gerenciar os recursos hídricos utilizando sistemas de captação e armazenamento (aproveitando os meses com altos índices pluviométricos) e, evitando a problemática da escassez de água.

Para que o desenvolvimento socioeconômico não seja limitado pela indisponibilidade hídrica é necessária políticas e planos para captação e aproveitamento das águas das chuvas, além do uso eficiente dos demais recursos naturais da região modificando o ciclo de discursos que culpa o clima pela falta de água esquecendo que as políticas públicas são sempre importantes para amenizar ou não os períodos de seca.

Permanece a necessidade de estudos mais aprofundados sobre a distribuição pluviométrica da região Nordeste do Brasil e em especial da região de São Bento do Una, visando à identificação de padrões de chuvas, medidas preventivas contra as secas e armazenamento de água para sobrevivência humana e animal.

Dentro das técnicas recomendadas existem as barragens subterrâneas que propiciam a exploração agrícola em sua bacia hidráulica, associado sempre a um poço amazonas em sua montante para investigações quanto ao nível do lençol freático retido e os níveis de sais.

A irregularidade no quantitativo e distribuição temporal da chuva é fatores limitantes para o desenvolvimento da produção avícola de São Bento do Una.

Obras em rios perenes, riachos, córregos ou encostas, semelhantes às barroquinhas, terraceamento com tiras de pneus, também são técnicas eficazes para a contenção de água no 
solo, para regiões onde ocorrem intensas chuvas em curto intervalo de tempo, e longo período de intervalo entre chuvas, além do pouco volume de água anual.

A utilização de dessalinizadores seria de fundamental importância para 0 desenvolvimento avícola local.

A principal necessidade que o munícipio deve realizar é fazer o reflorestamento dos cursos da água dos rios Una, Ipojuca e Riachão desta forma deixando os rios com escoamento e alterando a umidade de solo, alimentando o lençol freático regional e local.

A retirada excessiva do banco de areia do leito e vale dos rios vem prejudicando a infiltração das águas no solo deixando áridos.

A série temporal constituída dos totais máximos de precipitação mensal registrados a cada ano entre 1920-2016, não representa componentes significativas de correlação serial, tendências temporais ou periodicidades.

\section{AGRADECIMENTOS}

A Coordenação de Aperfeiçoamento de Pessoal de Nível Superior (CAPES) pela concessão de bolsa de Pós-doc e ao Departamento de Engenharia Ambiental pela pesquisa em desenvolvimento e o Centro de Inovação Tecnológica Aplicaa aos Recursos Naturais (CITAR).

\section{REFERÊNCIAS}

ALVARES, C.A.; STAPE, J.L.; SENTELHAS, P.C.; GONÇALVES, J.L.M.; SPAROVEK, G. Köppen's climate classification map for Brazil. Meteorologische Zeitschrift 22, 711-728. 2014.

AMANAJÁS, J.C.; BRAGA, C.C. Padrões Espaço-Temporal Pluviométricos na Amazônia Oriental utilizando Análise Multivariada. Revista Brasileira de Meteorologia, São José dos Campos/ SP, v.27, n.4, p.423-434, 2012.

APAC. Agencia pernambucana de água e clima. 2017. 
COSTA, M.S.; LIMA, K.C.; ANDRADE, M.M.; GONÇALVES, W.A. Tendências observadas em extremos de precipitação sobre a região Semiárida do Nordeste do Brasil. Revista Brasileira de Geografia Física. V 08. N 05. pag 1321-1334. 2015.

CPRM. Projeto cadastro de fontes de abastecimento por água subterrânea. P.26. 2005.

PEREIRA. E.R.R. Índices pluviométricos na análise da intensidade e variabilidade regional das chuvas no Nordeste do Brasil. Tese (Doutorado em Meteorologia), Campina Grande - PB, Universidade Federal de Campina Grande. 2014.

GALVANI, E. Estatística descritiva em sala de aula. In: VENTURI, L. A.B. Geografia: Práticas de campo, laboratório e sala de aula. São Paulo: Editora Sarandi, 2011.

GALVÍNCIO, J.D. Impactos dos eventos El Niño na precipitação da Bacia do rio São Francisco. Dissertação de Mestrado em Meteorologia, Campina Grande. Universidade Federal da Paraíba (PB), p.117, 2000.

INTERGOVERNMENTAL PANEL ON CLIMATE CHANGE Climate Change 2007: The Physical Science Basis, Contribution of Working Group I to the Fourth Assessment Report of the Intergovernmental Panel on Climate Change, edited by S. Solomon et al., Cambridge Univ. Press, Cambridge, U. K. 2014.

KÖPPEN, W.; GEIGER, R. "Klimate der Erde. Gotha: Verlag Justus Perthes”. Wall-map $150 \mathrm{~cm} x 200 \mathrm{~cm} .1928$.

LAMEPE. Laboratório de Meteorologia do Estado de Pernambuco. 2005

MARENGO, J.A.; ALVES, L.M.; BESERRA, E.A.; LACERDA, F.F. Variabilidade e mudanças climáticas no semiárido brasileiro. Recursos hídricos em regiões áridas e semiáridas. ISBN 978-85-64265-01-1. INSA. Pag. 303 - 422. Campina Grande-PB. 2011.

MEDEIROS, R.M.; HOLANDA, R. M.; VIANA, M. A.; SILVA, V. P. Climate classification in Köppen model for the state of Pernambuco - Brazil. Revista de Geografia (Recife). , v.35, 
p.219 - 234, 2018.

MEDEIROS, R.M. Fatores provocadores e/ou inibidores de chuvas no estado de Pernambuco. 2016.

MEDEIROS, R.M.; MATOS, R.M.; SILVA, P.F.; SABOYA, L.M.F. Cálculo do balanço hídrico e da erosividade para o município de Cabaceiras-PB. ENCICLOPÉDIA BIOSFERA, Centro Científico Conhecer - Goiânia, v.11. n.21; p. 2015.

MOURA, M. Padrões climáticos de precipitação e a produção de soja na Amazônia Dissertação (Mestrado em Ciências ambientais) - Instituto de Geociências, Universidade Federal do Pará,Belém. 2014.

SOUSA, N.M.N.; DANTAS, R.T.; LIMEIRA, R.C. Influência de variáveis meteorológicas sobre a incidência do dengue, meningite e pneumonia em João Pessoa-PB. Revista Brasileira de Meteorologia, v.22, n.2, p. 183-192, 2015.

SUN, X. et al. A general regional frequency analysis framework for quantifying local-scale climate effects: A case study of ENSO effects on Southeast Queensland rainfall. Journal of Hydrology, v. 512, p. 53-68, 2014.

TEIXEIRA, C.F.A. et al. Intensidade da seca utilizando índices de precipitação. Revista Ambiente e Água, Taubaté, v. 8, n. 3, 2013

WAYLEN, P.; OWUSU, K. Changes in expectations and extremes in the rainfall climatology of Accra, Ghana, 1895-2005. Applied Geography, v. 52, p. 99-109, 2014. 